NASA/TM-2002-210729

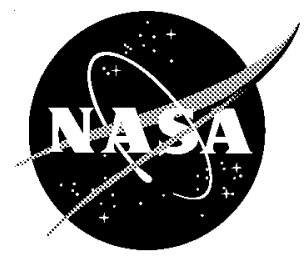

\title{
An Overview of Flight Test Results for a Formation Flight Autopilot
}

Curtis E. Hanson, Jack Ryan, Michael J. Allen, and Steven R. Jacobson NASA Dryden Flight Research Center

Edwards, California

August 2002 


\section{The NASA STI Program Office...in Profile}

Since its founding, NASA has been dedicated to the advancement of aeronautics and space science. The NASA Scientific and Technical Information (STI) Program Office plays a key part in helping NASA maintain this important role.

The NASA STI Program Office is operated by Langley Research Center, the lead center for NASA's scientific and technical information. The NASA STI Program Office provides access to the NASA STI Database, the largest collection of aeronautical and space science STI in the world. The Program Office is also NASA's institutional mechanism for disseminating the results of its research and development activities. These results are published by NASA in the NASA STI Report Series, which includes the following report types:

- TECHNICAL PUBLICATION. Reports of completed research or a major significant phase of research that present the results of NASA programs and include extensive data or theoretical analysis. Includes compilations of significant scientific and technical data and information deemed to be of continuing reference value. NASA's counterpart of peer-reviewed formal professional papers but has less stringent limitations on manuscript length and extent of graphic presentations.

- TECHNICAL MEMORANDUM. Scientific and technical findings that are preliminary or of specialized interest, e.g., quick release reports, working papers, and bibliographies that contain minimal annotation. Does not contain extensive analysis.

- CONTRACTOR REPORT. Scientific and technical findings by NASA-sponsored contractors and grantees.
- CONFERENCE PUBLICATION. Collected papers from scientific and technical conferences, symposia, seminars, or other meetings sponsored or cosponsored by NASA.

- SPECIAL PUBLICATION. Scientific, technical, or historical information from NASA programs, projects, and mission, often concerned with subjects having substantial public interest.

- TECHNICAL TRANSLATION. Englishlanguage translations of foreign scientific and technical material pertinent to NASA's mission.

Specialized services that complement the STI Program Office's diverse offerings include creating custom thesauri, building customized databases, organizing and publishing research results...even providing videos.

For more information about the NASA STI Program Office, see the following:

- Access the NASA STI Program Home Page at http://www.sti.nasa.gov

- E-mail your question via the Internet to help@sti.nasa.gov

- Fax your question to the NASA Access Help Desk at (301) 621-0134

- Telephone the NASA Access Help Desk at (301) 621-0390

- Write to:

NASA Access Help Desk

NASA Center for AeroSpace Information 7121 Standard Drive Hanover, MD 21076-1320 
NASA/TM-2002-210729

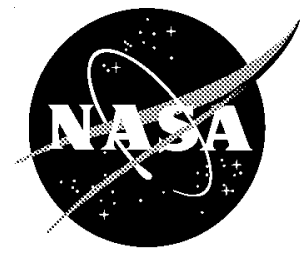

\section{An Overview of Flight Test Results for a Formation Flight Autopilot}

Curtis E. Hanson, Jack Ryan, Michael J. Allen, and Steven R. Jacobson NASA Dryden Flight Research Center

Edwards, California

National Aeronautics and

Space Administration

Dryden Flight Research Center

Edwards, California 93523-0273

August 2002 


\section{NOTICE}

Use of trade names or names of manufacturers in this document does not constitute an official endorsement of such products or manufacturers, either expressed or implied, by the National Aeronautics and Space Administration.

Available from the following:

NASA Center for AeroSpace Information (CASI)

7121 Standard Drive

Hanover, MD 21076-1320

(301) 621-0390
National Technical Information Service (NTIS) 5285 Port Royal Road Springfield, VA 22161-2171

(703) $487-4650$ 


\title{
AN OVERVIEW OF FLIGHT TEST RESULTS FOR A FORMATION FLIGHT AUTOPILOT
}

\author{
Curtis E. Hanson, ${ }^{*}$ Jack Ryan, ${ }^{\dagger}$ Michael J. Allen, ${ }^{\dagger}$ and Steven R. Jacobson ${ }^{\S}$ \\ NASA Dryden Flight Research Center \\ Edwards, California
}

\begin{tabular}{|c|c|c|}
\hline \multirow[b]{2}{*}{ The first flight test phase of the NASA Dryden Flight } & C & controller \\
\hline & CMD & command \\
\hline \multirow{7}{*}{$\begin{array}{l}\text { Research Center Autonomous Formation Flight project } \\
\text { has successfully demonstrated precision autonomous } \\
\text { station-keeping of an F/A-18 research airplane with a } \\
\text { second F/A-18 airplane. Blended inertial navigation } \\
\text { system (INS) and global positioning system (GPS) } \\
\text { measurements have been communicated across an } \\
\text { air-to-air telemetry link and used to compute } \\
\text { relative-position estimates. A precision research } \\
\text { formation autopilot onboard the trailing airplane } \\
\text { controls lateral and vertical spacing while the leading } \\
\text { airplane operates under production autopilot control. }\end{array}$} & $e$ & error signal \\
\hline & ERR & error \\
\hline & FILT & filtered \\
\hline & $G$ & low-pass filter \\
\hline & GPS & global positioning system \\
\hline & $\mathrm{I}$ & integral \\
\hline & INS & inertial navigation system \\
\hline \multirow{8}{*}{$\begin{array}{l}\text { Four research autopilot gain sets have been designed and } \\
\text { flight-tested, and each exceeds the project design } \\
\text { requirement of steady-state tracking accuracy within } 1 \\
\text { standard deviation of } 10 \mathrm{ft} \text {. Performance also has been } \\
\text { demonstrated using single- and multiple-axis inputs } \\
\text { such as step commands and frequency sweeps. This } \\
\text { report briefly describes the experimental formation } \\
\text { flight systems employed and discusses the navigation, } \\
\text { guidance, and control algorithms that have been } \\
\text { flight-tested. An overview of the flight test results of the } \\
\text { formation autopilot during steady-state tracking and } \\
\text { maneuvering flight is presented. }\end{array}$} & $\mathrm{K}$ & gain \\
\hline & $n_{1}$ & GPS relative-position error \\
\hline & $n_{2}$ & INS relative-position error \\
\hline & $N$ & navigation \\
\hline & $\mathrm{Nz}$ & normal acceleration \\
\hline & $\mathrm{P}$ & position \\
\hline & PSFCC & production support flight control computer \\
\hline & $s$ & Laplace operator \\
\hline$\underline{\text { Nomenclature }}$ & SRA & Systems Research Aircraft \\
\hline Autonomous Formation Flight & $t$ & time \\
\hline \multirow[t]{2}{*}{ ARTS Airborne Research Test System } & $\mathrm{V}$ & velocity \\
\hline & $x_{1}$ & GPS relative-position measurement \\
\hline \multirow{3}{*}{$\begin{array}{l}\text { *Aerospace Engineer. } \\
\text { † Aerospace Engineer. } \\
\text { †Aerospace Engineer. } \\
\text { §Aerospace Engineer. }\end{array}$} & $x_{2}$ & INS relative-position measurement \\
\hline & $\mathrm{X}$ & state \\
\hline & & true relative position \\
\hline \multirow{3}{*}{$\begin{array}{l}\text { Copyright (c) } 2002 \text { by the American Institute of Aeronautics and } \\
\text { Astronautics, Inc. No copyright is asserted in the United States under } \\
\text { Title } 17 \text {, U.S. Code. The U.S. Government has a royalty-free license } \\
\text { to exercise all rights under the copyright claimed herein for } \\
\text { Governmental purposes. All other rights are reserved by the copyright } \\
\text { owner. }\end{array}$} & $\varepsilon$ & uncertainty \\
\hline & $\phi$ & bank angle \\
\hline & $\wedge$ & estimate \\
\hline
\end{tabular}




\section{$\underline{\text { Introduction }}$}

A formation autopilot capable of precise station-keeping is required for applications such as formation flight drag reduction. Formation flight shows significant promise to improve efficiency through cooperative aircraft operations. In a manner similar to migrating flocks of birds, aircraft in formation can take advantage of the vortex upwash created by the aircraft ahead of them, allowing them to operate more efficiently. Flight tests that showed drag reduction by measuring power reduction were first performed in Germany in $1990 .^{1}$ Beukenberg and Hummel successfully tested an optimization technique and measured an average power reduction of approximately 10 percent. ${ }^{1,2}$ One limitation of their approach was a lack of intership communication that prevented coordination among the aircraft within the formation.

The objective of the NASA Dryden Flight Research Center (Edwards, California) Autonomous Formation Flight (AFF) project has been to develop and flight-test a formation autopilot system capable of achieving sustained drag reduction by exploiting robust intership communication and precise formation navigation and control. The AFF project had three planned phases; beginning with autonomous station-keeping without drag reduction, then proceeding to the piloted mapping of wingtip vortex locations and effects, and finally culminating with the testing of an autonomous drag reduction system. The project, however, was cancelled shortly after completion of the second phase.

The first phase of the AFF project, named "Phase 0," has successfully demonstrated precision autonomous station-keeping of two aircraft in flight. Although flight within the vortex was not the intention of this phase of the program, the station-keeping flight tests discussed herein are the first steps in that development. Two NASA Dryden-owned F/A-18 (McDonnell Douglas Corporation, now The Boeing Company, St. Louis, Missouri; and Northrop Corporation, now Northrop Grumman, Newbury Park, California) research aircraft were outfitted with identical global positioning system (GPS) receivers and an air-to-air telemetry system for intership communication. In addition, the trailing airplane was equipped with an experimental precision formation autopilot control system. Using GPS and inertial measurement data from both aircraft, the experimental system computed the equivalent of pilot stick commands to fly the trailing airplane to the desired position within the formation.
A total of 167 test points have been accomplished in 11 research flights over a period of 2 months. This report briefly describes the experimental formation flight systems employed and discusses the navigation, guidance, and control algorithms that were flight-tested. An overview of the flight test results of the formation autopilot during steady-state tracking and maneuvering flight is presented.

Note that use of trade names or names of manufacturers in this document does not constitute an official endorsement of such products or manufacturers, either expressed or implied, by the National Aeronautics and Space Administration.

\section{$\underline{\text { Research Objectives }}$}

The ultimate goal of the AFF project has been to bring AFF technology and its associated drag reduction benefits to a readiness level that will be attractive to commercial cargo operators and the military. Additional applications of AFF technology include autonomous aerial refueling, low-visibility formation separation assurance, and uninhabited combat air vehicle pack and swarm operations.

The objective of the initial phase (Phase 0 ) of the AFF research has been to reduce the programmatic risks for achieving drag reduction through autonomous formation flight. Although pilots regularly achieve very accurate formation spacing, an automatic system is desirable for reducing pilot workload, particularly on long-endurance missions. Data were sought regarding the feasibility of using GPS for formation navigation and the achievable control precision of a formation autopilot.

Phase 0 of the experiment evaluated a wide range of formation autopilot performance and robustness levels to provide guidance to future formation flight control system designers. Flight test measurements also helped validate and improve the project design tools in preparation for the next phases of the project. Much of the systems integration effort accomplished and tested by NASA Dryden during Phase 0 was also to be used for the planned drag reduction tests.

\section{Design Requirements}

The formation autopilot controlled only the lateral and vertical motion of the airplane because hardware restrictions limited the number of available command outputs to two. The primary design goal has been to achieve precision tracking during steady, level flight. 
Performance requirements for the formation autopilot specify that the formation control accuracy be within 1 standard deviation of $10 \mathrm{ft}$. This position-error budget is partitioned into two categories: navigation uncertainty, and controller performance. These two random and uncorrelated error sources are combined as the root of the sum of their squares:

$$
\varepsilon=\sqrt{\varepsilon_{N}^{2}+\varepsilon_{C}^{2}}
$$

where $\varepsilon$ is the total uncertainty, $\varepsilon_{N}$ is the navigation uncertainty, and $\varepsilon_{C}$ is the uncertainty in controller performance. Navigation uncertainty has been allocated $\pm 4 \mathrm{ft}$ based upon the results of preliminary piloted risk-reduction flight tests. The remaining approximately $\pm 9 \mathrm{ft}$ of position error is the performance design goal of the formation autopilot.

Three levels of stability robustness requirements (table 1) have been defined to allow the full range of formation autopilot performance levels to be evaluated. The high and medium categories are based upon the military specification ${ }^{3}$ robustness requirements for modes greater and less than $0.06 \mathrm{~Hz}$, respectively. The low category is consistent with the minimum flight-demonstrated margins for the X-29 aircraft. ${ }^{4}$

Table 1. Stability robustness requirements.

\begin{tabular}{ccc}
\hline \hline $\begin{array}{c}\text { Robustness } \\
\text { level }\end{array}$ & $\begin{array}{c}\text { Gain margin, } \\
\mathrm{dB}\end{array}$ & $\begin{array}{c}\text { Phase margin, } \\
\mathrm{deg}\end{array}$ \\
\hline High & 6.0 & 45 \\
Medium & 4.5 & 30 \\
Low & 3.0 & 20 \\
\hline \hline
\end{tabular}

The NASA Dryden F/A-18 "Class B" flight envelope defines operational limits within which simulation analysis has shown that any combination of fully deflected control surfaces will not cause structural damage to the aircraft nor put the aircraft in an unrecoverable condition. This envelope is bounded by a maximum airspeed of 250-kn calibrated airspeed and an altitude range from 20,000 to $32,000 \mathrm{ft}$. A single design condition has been selected within this envelope: Mach 0.56 and an altitude of $25,000 \mathrm{ft}$. This point is in the middle of the Class $B$ altitude range and is at a reasonably high dynamic pressure for good aircraft controllability. The single-point design has been evaluated in the simulation and cleared for operation within an altitude band of 20,000-30,000 ft at a constant indicated airspeed.

\section{$\underline{\text { Research Systems Overview }}$}

The research systems primarily have been developed from existing capabilities at NASA Dryden and integrated onto the two F/A-18 research aircraft. Elements from past and current research experiments include instrumentation systems on both aircraft, an air-to-air telemetry system, a research computer, a flight crew interface, and a set of specially modified F/A-18 flight control computers. This approach reduced cost and development time for the experiment.

\section{$\underline{\text { Research Aircraft Description }}$}

Figure 1 shows the two NASA Dryden F/A-18 aircraft used for this experiment. A two-seat chase-support airplane equipped with a GPS receiver and a telemetry system served as the leading airplane; the Systems Research Aircraft (SRA) served as the trailing one. In addition to its research instrumentation, GPS receiver, and telemetry modifications; ${ }^{5}$ the SRA was outfitted with the experimental formation flight systems described in the following section. A third NASA Dryden chase-support airplane was occasionally used for video and photographic documentation of the experiment.

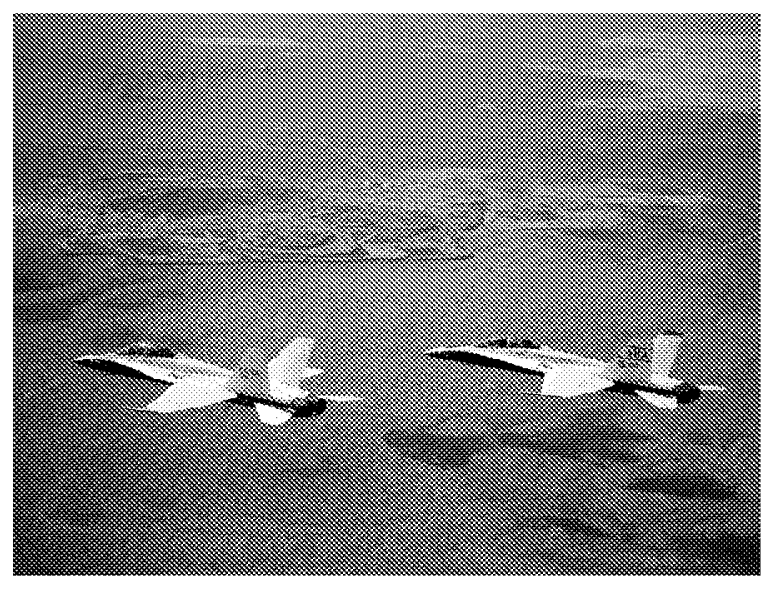

EC01-0050-9

Figure 1. The NASA F/A-18 AFF research aircraft in formation flight.

\section{Formation Flight Systems Overview}

The formation flight systems were located on the trailing airplane and integrated an air-to-air telemetry receiving system and a research flight control system. The telemetry system was used for intership communication, and the control system computed 
formation station-keeping commands. These commands replaced the pilot stick commands in the F/A-18 inner-loop control system. Other than the quadruply-redundant F/A-18 flight control computers, the experimental systems were single-string. Figure 2 shows the formation flight systems.

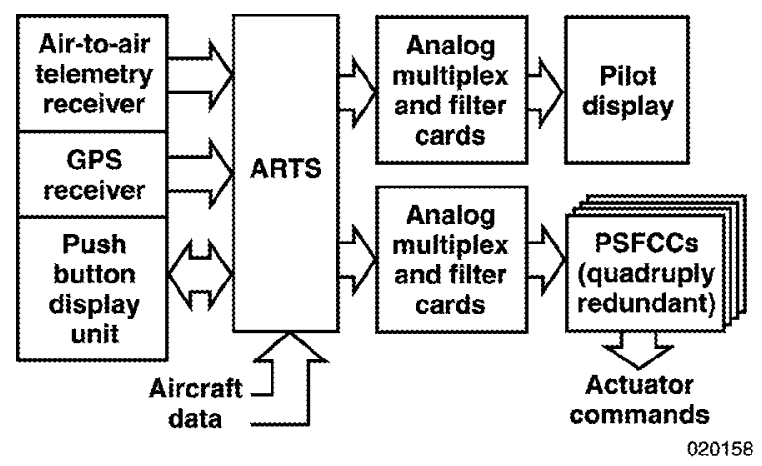

Figure 2. The trailing airplane formation flight systems.

Inertial state information and GPS position data telemetered from the leading airplane were received and decoded by the Airborne Research Test System (ARTS) computer onboard the trailing airplane. A real-time embedded system, the ARTS also contained the formation autopilot software that calculated pitch and roll stick commands to maintain the desired position of the trailing airplane within the formation. The single-string analog pitch and roll commands were sent from the ARTS to a set of analog multiplex and filter cards. ${ }^{6}$ These cards applied a $40-\mathrm{Hz}$ low-pass filter to each command and multiplexed them into four identical signals. The signals interfaced with the four channels of the production support flight control computers (PSFCCs) and to a pilot display. These PSFCCs are specially modified F/A-18 flight control computers ${ }^{7,8}$ with software that allows selection between the pilot's pitch and roll stick commands and the external ARTS commands. A pushbutton display unit located in the aft cockpit of the trailing airplane and connected to the ARTS allowed the flight test engineer to monitor the status of the ARTS and change various parameters of the formation autopilot, such as spacing commands and feedback gains.

\section{Formation Autopilot}

A precision formation autopilot (fig. 3) has been designed to control the lateral and vertical separation of the trailing airplane with respect to the leading airplane in the formation. This control is accomplished by replacing the pilot control stick commands to the F/A-18 inner-loop control laws with the formation autopilot commands. The separation distance between the nose of the trailing airplane and the tail of the leading one is regulated by the pilot of the trailing one through throttle adjustments.

A leader-follower guidance and control approach is used. In this approach, the leading airplane has no responsibility for maintaining the formation and is merely required to pursue an independent flightpath. The trailing airplane is solely responsible for making all of the required maneuvers to achieve the desired

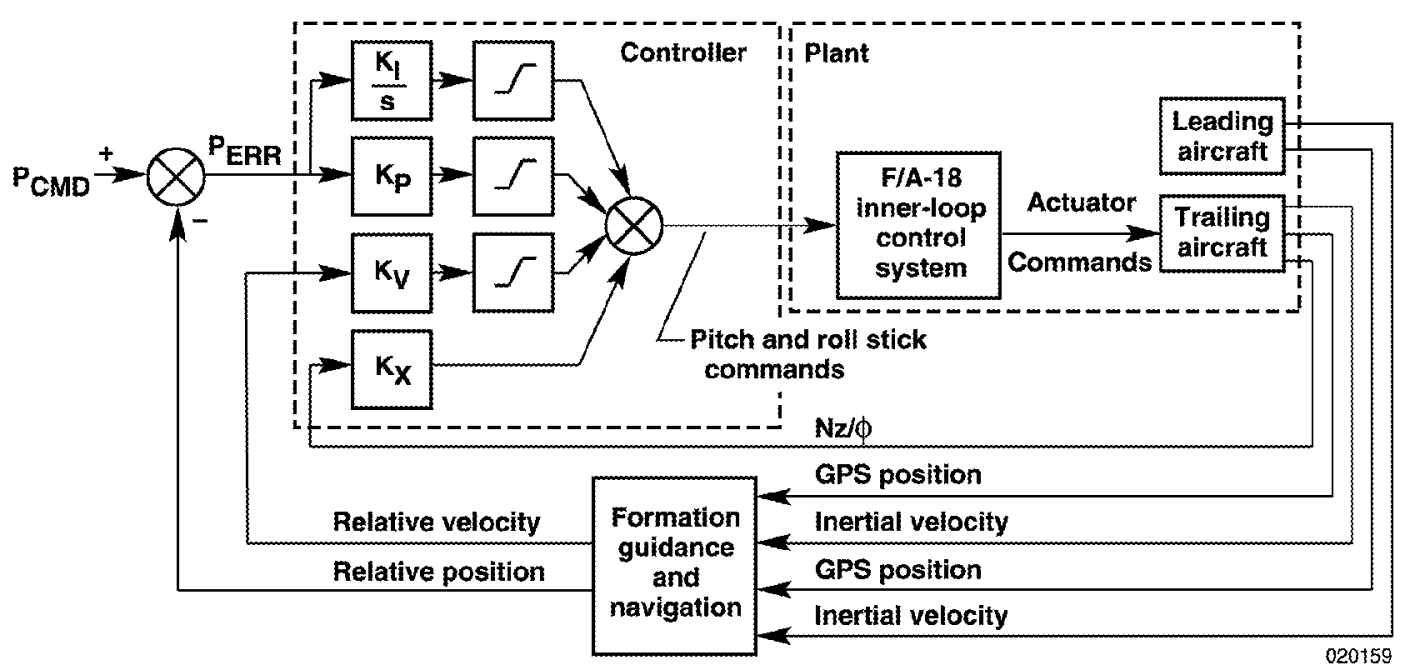

Figure 3. Formation autopilot. 
position behind the leading airplane; formation control is applied only to the trailing one. For design purposes, the operational concept for the formation autopilot is restricted to straight-and-level flight; however, some flight tests have been performed in dynamic conditions to fully evaluate the limitations of the system.

\section{Formation Guidance and Navigation}

Relative positions are calculated in a formation reference frame (fig. 4) that is fixed in alignment with the heading selected by the flight test engineer. This approach minimizes lateral spacing errors caused by fluctuations in one or both of the aircraft headings, a problem that can be magnified by increasingly large nose-to-tail separations.

Real-time relative positions between the two aircraft are derived at $20 \mathrm{~Hz}$ by time-correlating and then differencing their twice/sec GPS position measurements. ${ }^{9}$ With common satellites and close proximity between the aircraft, common mode errors such as ephemeris data errors, satellite clock errors, and atmospheric distortion effects are very nearly eliminated. ${ }^{10}$ The remaining dominant error is caused by the 2 samples/sec data being processed at $20 \mathrm{~Hz}$. The resulting GPS relative-position measurement therefore can be represented as

$$
x_{1}(t)=z(t)+n_{1}(t)
$$

where $x_{1}(t)$ is the GPS-measured position, $z(t)$ is the true position, and $n_{1}(t)$ is the measurement error.
A second relative-position measurement between the two aircraft is obtained by differencing and then integrating their inertial navigation system (INS) velocities at $20 \mathrm{~Hz}$. The primary errors in this measurement are low-frequency drift caused by biases in the INS velocities. The inertial position measurement therefore can be represented as

$$
x_{2}(t)=z(t)+n_{2}(t)
$$

where $x_{2}(t)$ is the INS-measured position, $z(t)$ is the true position, and $n_{2}(t)$ is the low-frequency error caused by integration drift.

The two independent relative-position measurements are combined together using a complementary filter ${ }^{11}$ to provide formation navigation information to the control algorithms (fig. 5). By subtracting one measurement from the other $\left(x_{2}-x_{1}\right)$, the error $\left(e=n_{2}-n_{1}\right)$ is obtained. A first-order low-pass filter,

$$
G(s)=\frac{0.25 \pi}{s+0.25 \pi}
$$

tuned to remove $n_{1}$ from $e$, provides $n_{2}$. Subtracting this result from the original inertial measurement $\left(z+n_{2}\right)$ produces an accurate relative-position measurement.

The complementary-filtered position estimate is differentiated to provide a velocity estimate with a reliable low-frequency component. This estimate is used to isolate and correct the inertial relative velocity measurement through a second complementary filter employing an identical first-order low-pass filter.

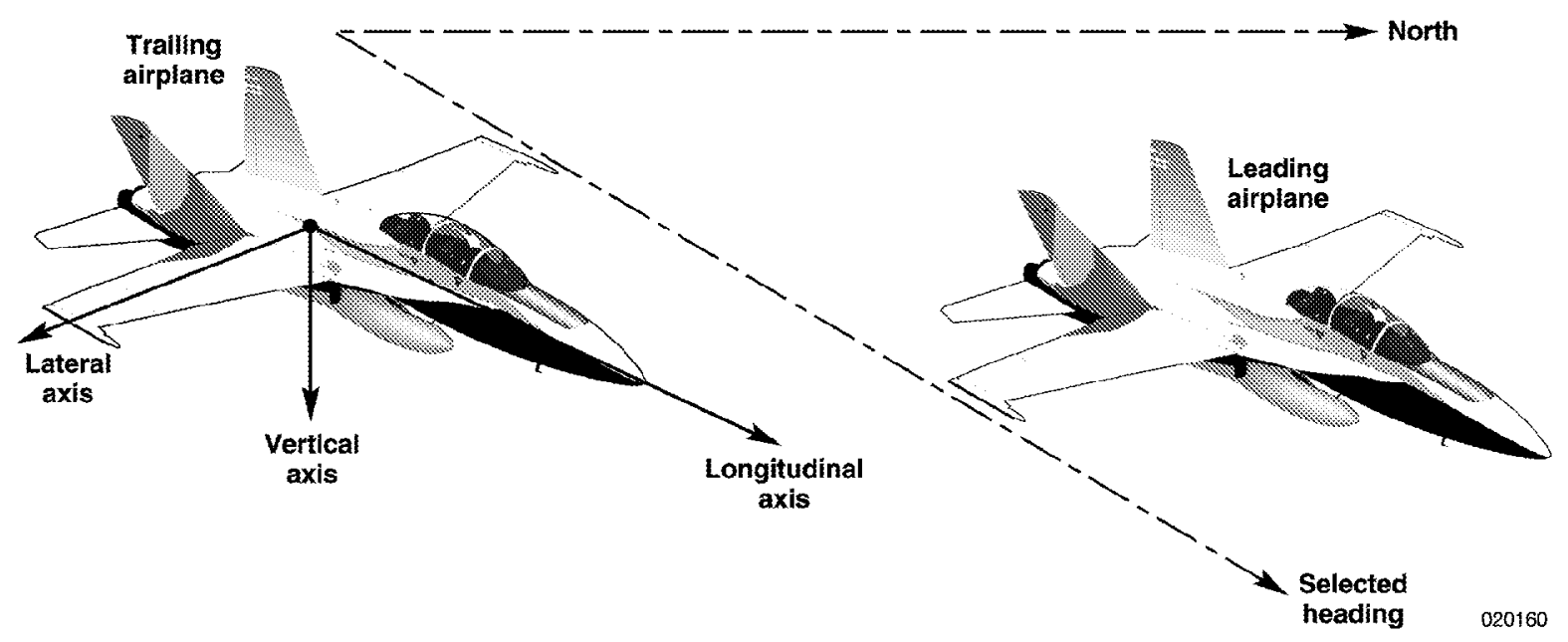

Figure 4. Formation reference frame. 


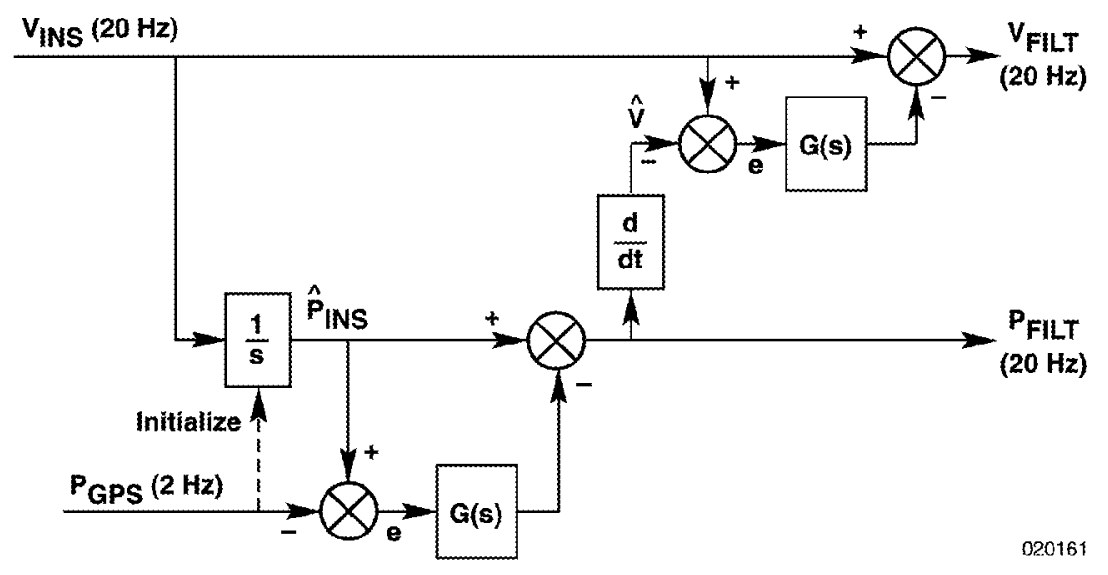

Figure 5. INS/GPS complementary filter.

Control feedback errors are calculated as nonzero relative velocities and deviations in relative position from the commanded formation spacing. These errors are provided to the formation autopilot control system and also are used to drive the pilot's display. Relative-position errors are displayed to the pilot as deviations of the instrument landing system needles. This implementation helps minimize engagement transients by assisting the pilot in "getting on condition" before activating the formation control system. During the experiment, the pilot could use the instrument landing system needles to monitor the performance of the formation autopilot.

\section{$\underline{\text { Position Control Algorithms }}$}

A classical control design employing proportional plus derivative relative-position error feedback (fig. 3), is used with additional state feedback for improved damping characteristics. An integral term is added to ensure zero steady-state position error. Acceptable damping is achieved in the vertical axis through normal acceleration feedback, and in the lateral axis through bank angle feedback. The controller uses the complementary-filtered position and velocity estimates as inputs, in addition to normal acceleration and bank angle from the local aircraft INS computer.

Four gain sets have been designed for each axis of the controller. Three of the gain sets $(\mathrm{A}, \mathrm{B}$, and $\mathrm{C})$ correspond to the three levels of stability robustness requirements shown in table 1 . The fourth gain set (D) is designed for the medium stability robustness category, but includes a nonzero position error integral gain. The gain sets have been tuned using a feasible sequential quadratic programming tool, CONDUIT, ${ }^{12}$ and an
F/A-18 model that contains the nonlinear aircraft inner-loop control system and a linear model of the dynamics of the trailing airplane. The design approach has been to optimize the controller response to a $1-\mathrm{ft}$ step command within specified constraints for rise time, percent of overshoot, settling time, and degree of steady-state error. Each axis has been separately tuned, with constraints placed on the allowable stability margins. The leading airplane has been excluded from the design process by virtue of the leader-follower approach and by considering its states as time invariant.

Because of differences between the quasilinear design models and the nonlinear, hardware-in-the-loop F/A-18 simulation, small adjustments have been made to the gains provided by CONDUIT to achieve the desired combinations of robustness and performance described in table 2. Stability margins have been analyzed by breaking the loop at the equivalent stick command, and in all cases met or exceeded their design requirements. All four gain sets have been implemented in the software and flight-tested.

Table 2. Controller gain sets.

\begin{tabular}{cl}
\hline \hline Gain set & \multicolumn{1}{c}{ Description } \\
\hline A & Highly robust and low performance \\
B & Medium robustness and performance \\
C & Low robustness and high performance \\
D & Medium robustness and performance \\
& with position error integral \\
\hline \hline
\end{tabular}




\section{Flight Test Results}

The leading airplane used production F/A-18 autopilot modes to maintain constant heading, altitude, and airspeed. Desired lateral, vertical, and nose-to-tail separation distances between the aircraft were selected by the flight test engineer through the pushbutton display. When the research system was engaged, the trailing airplane automatically made all of the adjustments necessary to correct for lateral and vertical relative-position errors from the specified location within the formation. Nose-to-tail separation was regulated by the pilot through throttle adjustments.

All testing was performed in formations that allowed the pilot of the trailing airplane good visibility of the leading airplane. A nose-to-tail separation limit between the two aircraft of $56 \mathrm{ft}$ was imposed to mitigate the possibility that errant pitch or roll inputs from the research system would result in a collision between the two aircraft while in formation flight. This limit equates to one aircraft body length, and ensured that adequate maneuvering room was available for the trailing airplane after the pilot disengaged the research control system.

The standard test block developed for the experiment reflects a buildup approach. A full evaluation of the stability and performance of the most robust gain set was accomplished before proceeding to the next gain set. Six types of maneuvers were defined that had increasing levels of aggressiveness. A steady-state tracking test was accomplished first, followed by position step command response tests independently performed in each axis. A position step then was commanded by the flight test engineer in the back seat of the trailing airplane simultaneously in both axes to evaluate coupling between the axes. Additional dynamic performance of the formation autopilot was evaluated by having the leading airplane perform maneuvers in first the lateral and then the vertical axis.

A total of 167 test points were completed in 11 research flights over a span of 2 months. All of the primary project goals were accomplished; and several additional research objectives were achieved, including tracking while in the wingtip vortex of the leading airplane. The flight test results are presented herein in five groups: air-to-air navigation, steady-state tracking, step command response, maneuvering flight, and flight within the vortex. $\underline{\text { Air-to-Air Navigation Accuracy }}$

The GPS-based air-to-air navigation system relied on common satellites and close proximity between the aircraft. Close proximity was assured through the selection of test conditions. During the final six flights, the two aircraft observed different satellite sets only twice while in formation flight. Large GPS position errors occurred in these situations. A change in the formation heading resulted in the reacquisition of common satellites. Although close formation flight aided in ensuring common satellites between the aircraft, it also tended to give rise to telemetry system communication dropouts caused by multipath interference.

The accuracy of the air-to-air navigation system was evaluated by comparing the real-time recorded measurements with postflight-corrected GPS data. Postflight-corrected GPS data measurements have been shown through experimentation at NASA Dryden to be accurate to within $1 \mathrm{ft}$. Figure 6 shows a plot of the difference between the real-time-calculated and postflight-corrected GPS relative positions for each axis during the entire time at altitude for one of the AFF test flights. Figure 6 also shows the normalized error distribution for each axis. The error distributions show that the uncertainty in relative GPS positions was generally less than $\pm 4 \mathrm{ft}$.

\section{Steady-State Tracking Performance}

During all of the flights, the pilots reported turbulence levels ranging from "no turbulence" to "light chop." A slight degradation in tracking performance was observed with increased turbulence levels, although control accuracy was always better than the design goal of $\pm 9 \mathrm{ft}$. Figure 7 shows a 3 -min tracking performance plot of the "A" gain formation autopilot. The pilot of the leading airplane performed all of the steady-state tracking tests in a consistent manner, flying within $0.25^{\circ}$ of the formation reference frame heading and with less than $0.25^{\circ}$ of bank angle. Additionally, rudder trim deflection was less than $1^{\circ}$ with the pilot flying "feet on the floor."

Occasionally, significant biases existed between the INS velocities of the two aircraft because they had slightly different INS systems, and preflight operations often resulted in unequal alignment qualities prior to takeoff. Figure 8 shows a comparison of the normalized heading alignment and INS velocity errors between the two aircraft for the entirety of flight 715 . 

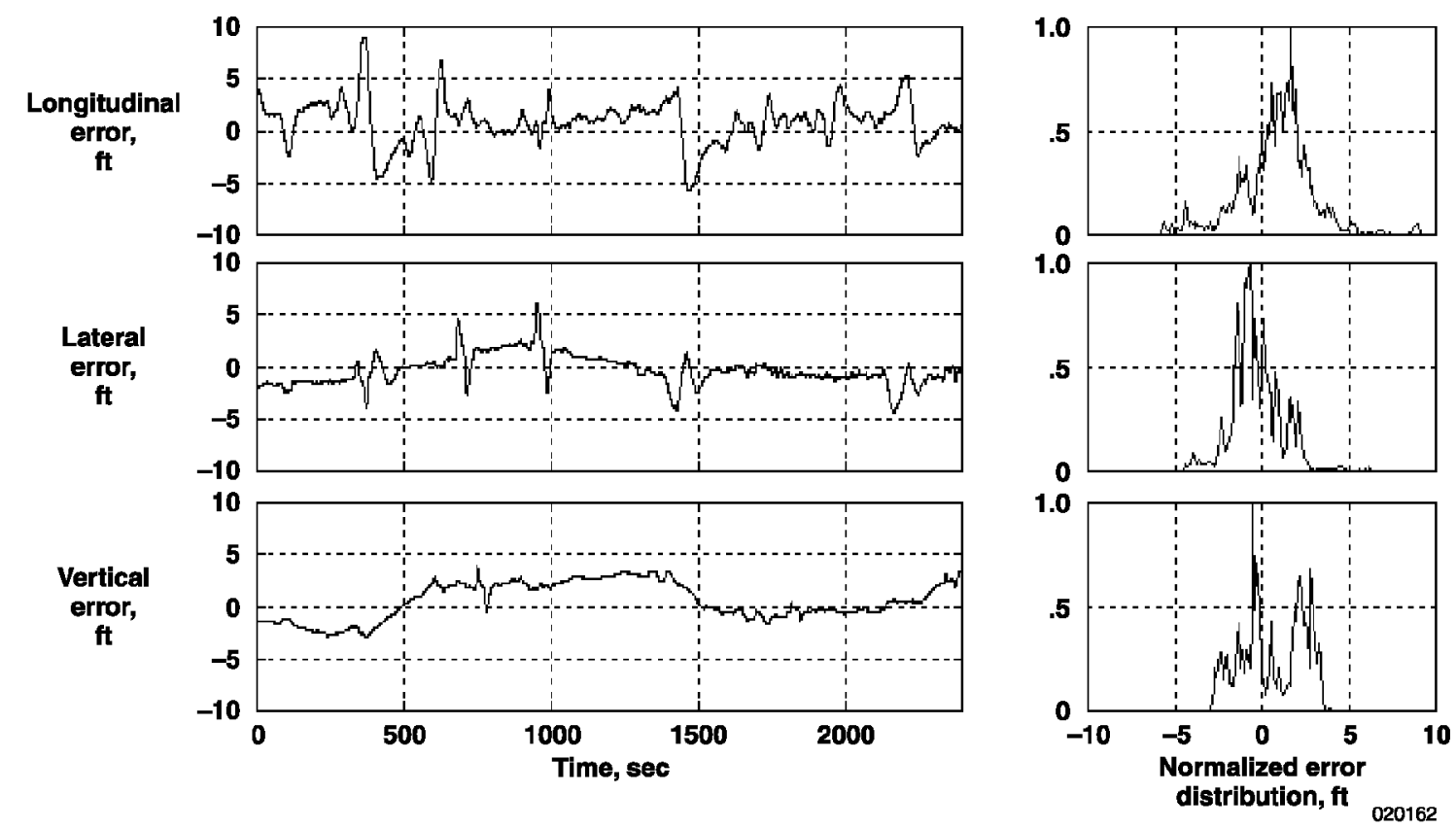

Figure 6. Relative GPS errors from flight 713.

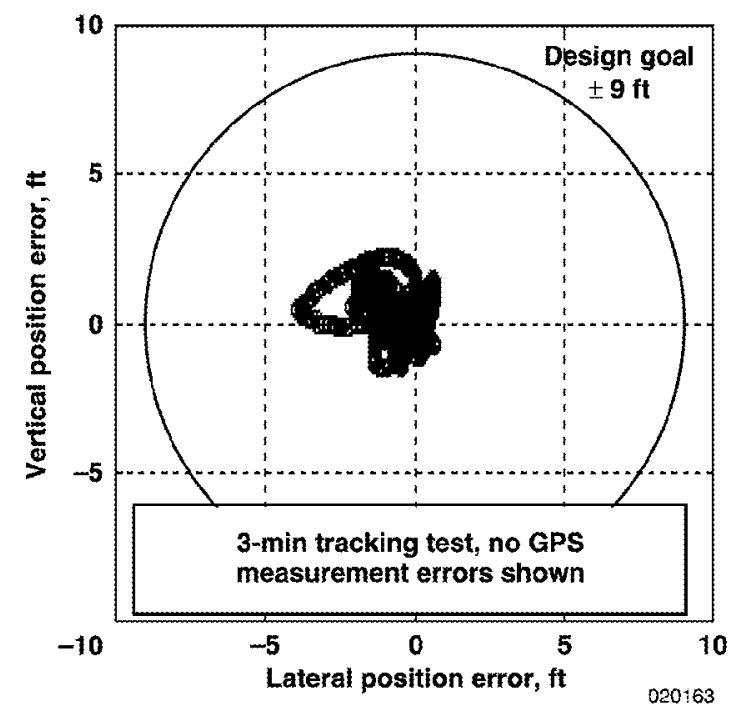

Figure 7. Flight 714 gain set "A" steady-state tracking performance. 

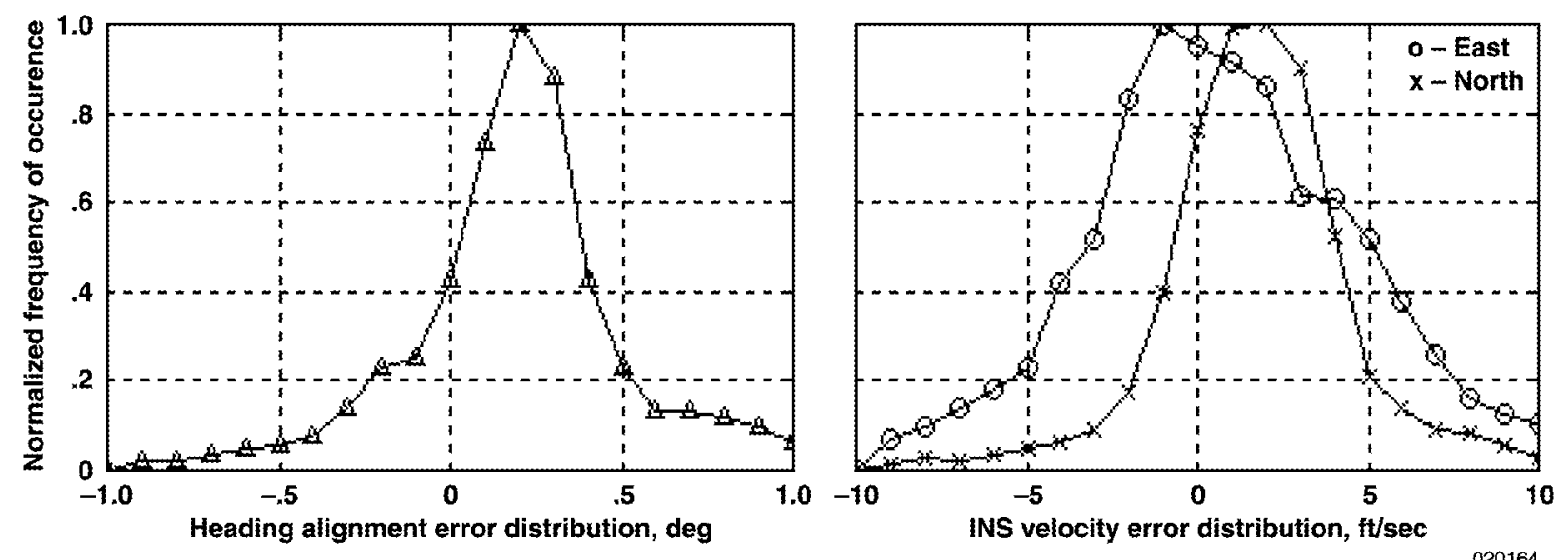

Figure 8. INS alignment errors from flight 715.

These heading alignment errors resulted in a biased relative-velocity calculation. The complementary filter combined the derivative of the GPS-corrected position data with the INS velocities, effectively eliminating this bias. The relative-velocity feedback signal to the controller was selectable between filtered and unfiltered values by the flight test engineer using the pushbutton display unit. Figure 9 shows a portion of the gain set "B" steady-state tracking test from flight 715 during which the velocity filter was activated. During the time in which the unfiltered velocity error was being sent to the controller, the linear controller developed a large, lateral position offset while attempting to counteract the effects of the lateral velocity error bias. When the filtered output was selected, the tracking performance of the formation autopilot improved significantly.

Table 3 shows a summary of the steady-state tracking performance of the four gain sets. No GPS errors are included and only results with the velocity filter engaged are considered.

\section{$\underline{\text { Step Command Response }}$}

Step response characteristics of all four gain sets were crisp and predictable. Pilot comments indicate that gain set " $\mathrm{C}$ " is a little too aggressive, although acceptable.
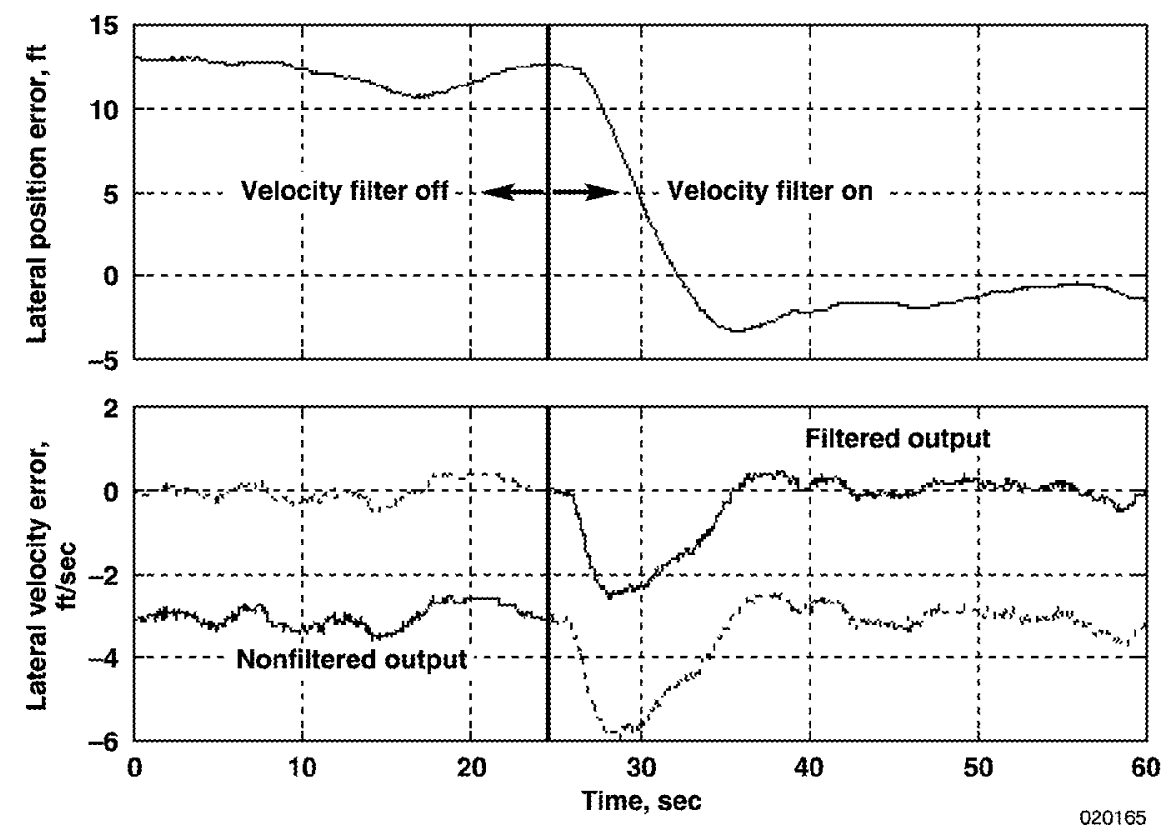

Figure 9. Velocity filter effects on gain set "B" tracking from flight 715. 
Table 3. Controller tracking performance summary.

\begin{tabular}{ccccc}
\hline \hline & \multicolumn{2}{c}{ Lateral axis } & \multicolumn{2}{c}{ Vertical axis } \\
\cline { 2 - 5 } $\begin{array}{c}\text { Gain } \\
\text { set }\end{array}$ & $\begin{array}{c}\text { Standard } \\
\text { deviation, } \mathrm{ft}\end{array}$ & $\begin{array}{c}\text { Absolute } \\
\text { mean, } \mathrm{ft}\end{array}$ & $\begin{array}{c}\text { Standard } \\
\text { deviation, } \mathrm{ft}\end{array}$ & $\begin{array}{c}\text { Absolute } \\
\text { mean, } \mathrm{ft}\end{array}$ \\
\hline $\mathrm{A}$ & 0.9 & 0.8 & 0.8 & 0.3 \\
$\mathrm{~B}$ & 0.5 & 0.0 & 0.3 & 0.2 \\
$\mathrm{C}$ & 0.3 & 0.3 & 0.5 & 0.1 \\
$\mathrm{D}$ & 0.8 & 0.2 & 0.6 & 0.1 \\
\hline \hline
\end{tabular}

Note: No GPS errors included; results with velocity filter on.

The pilot's description of the combined step response of gain set "B" is "[I] couldn't have done it any better myself." Figure 10 shows a comparison between the gain set "B" design model response predictions and six repeated flight test results for independent $30-\mathrm{ft}$ position command changes for both axes. A high level of correlation exists between the model predictions and results from flight for all four gain sets. Variations between the flight responses, especially in the lateral axis, primarily are a result of a nonsteady-state initial condition.

Lateral and vertical position steps simultaneously were commanded to identify any cross-coupling between the axes. Figure 11 shows the response of gain set "C" for simultaneous vertical and lateral $20-\mathrm{ft}$ position command changes. During the combined steps for each of the gain sets, no significant coupling was observed between the axes, and pitch response generally was faster than roll response.

\section{Maneuvering Flight}

Dynamic response of the lateral position controller was tested by having the leading airplane fly heading sweeps of increasing magnitude. Although some phase lag, approximately $45^{\circ}$, was evident in the lateral position response of the trailing airplane (fig. 12), no instabilities were observed. The tracking performance of the system deteriorated to worse than the design goal of $\pm 9 \mathrm{ft}$ for all four gain sets, partly because of the effect of varying aircraft heading while measuring errors relative to a fixed formation heading. The stable dynamic response of the system is acceptable, however, because it was designed strictly for nonmaneuvering flight.

Dynamic response of the vertical position controller was observed during a series of slowly increasing altitude sweeps performed by the leading airplane (fig. 13). Significantly less phase lag was present in the vertical axis than in the lateral axis. The vertical axis commands pitch stick, which in the F/A-18 aircraft essentially is a normal acceleration command, analogous to the second derivative of the vertical

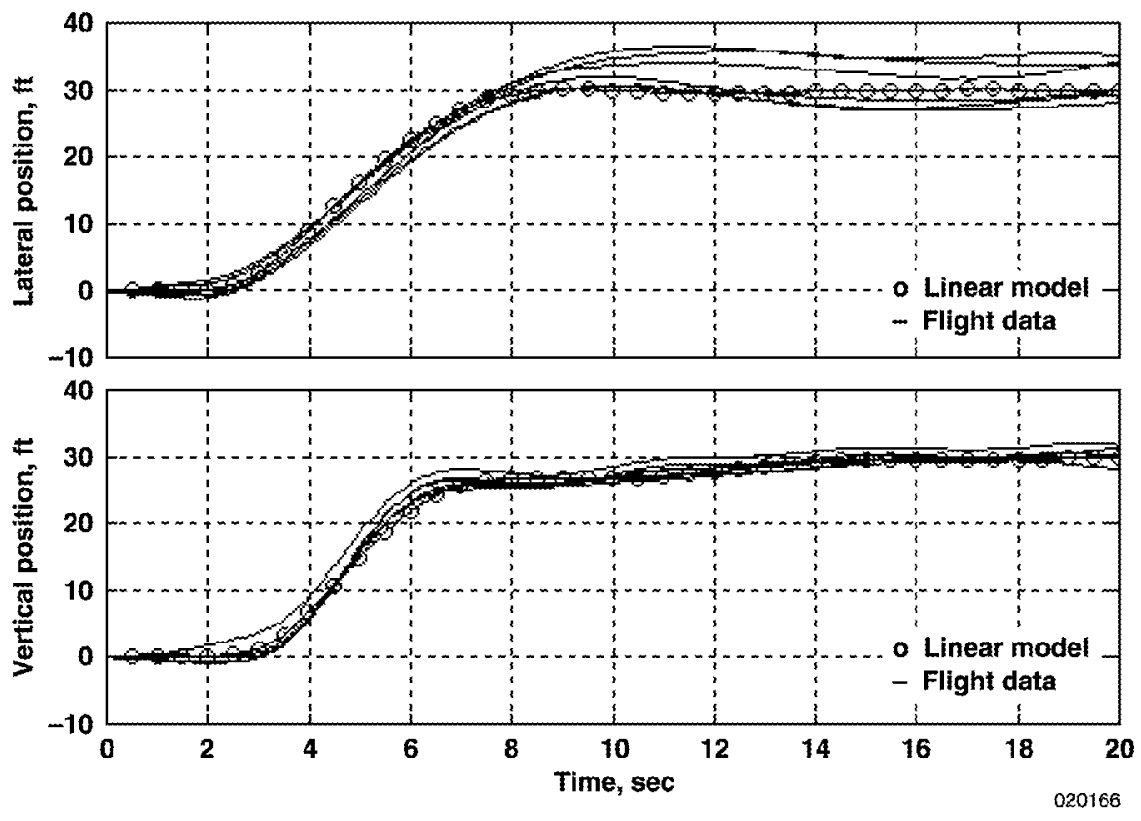

Figure 10. Gain set "B" individual step responses. 


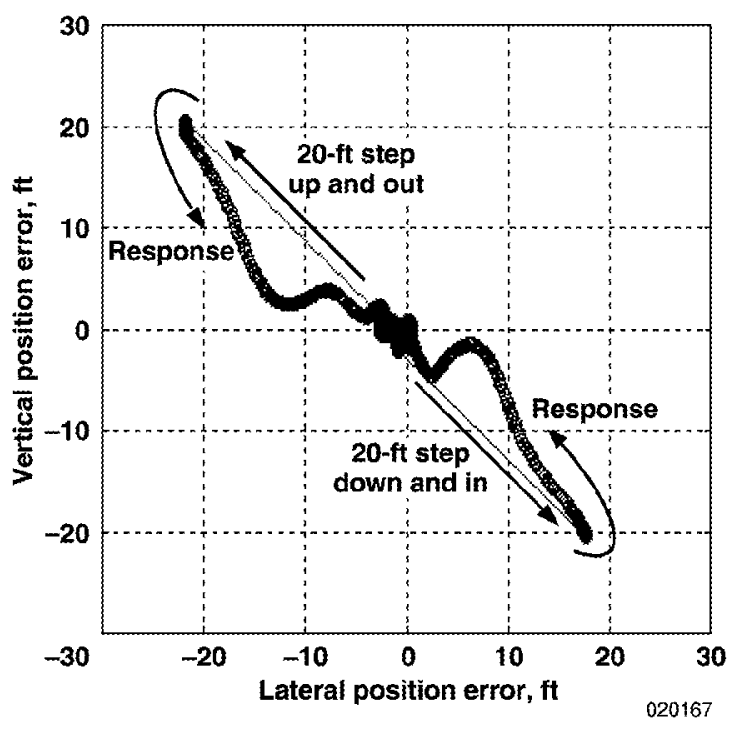

Figure 11. Gain set "C" combined step error response from flight 717.

position error. The lateral stick command controls roll rate, which is analogous to the third derivative of the lateral position error. The additional integral from command to response in the lateral axis results in greater phase lag. The vertical tracking error for this test also exceeded the \pm 9 -ft design requirement; however, vertical tracking is stable and adequately tracks the leading airplane, considering it was designed for only straight-and-level flight.
The tracking performance of the vertical controller gain set " $D$ " was evaluated in a steady dive, initiated by the pilot of the leading airplane, from an altitude of $22,500 \mathrm{ft}$ at a rate of descent of approximately $2000 \mathrm{ft} / \mathrm{min}$. The heading and airspeed were held constant. As figure 14 shows, the controller was able to very accurately maintain the desired position within the formation during the descent.

\section{Flight Within the Vortex}

Although beyond the scope of the original objectives, the Phase 0 formation autopilot was tested in the presence of the leading airplane wingtip vortex to learn whether the current controller structure is adequate to achieve the Phase 1 objective of autonomous formation drag reduction. A model of the vortex was incorporated into the NASA Dryden F/A-18 hardware-in-the-loop simulation for this purpose. The most significant vortex disturbance when positioned for maximum drag reduction is a strong rolling moment effect. ${ }^{13}$ Gain set " $D$ " was chosen for evaluation because of the ability of its position error integral term to generate a lateral command bias to offset the vortex rolling moment. The simulation showed that the formation autopilot can stabilize within the outer regions of the vortex where the moment effects are not the strongest, but the system becomes unstable when flown near the core of the vortex.
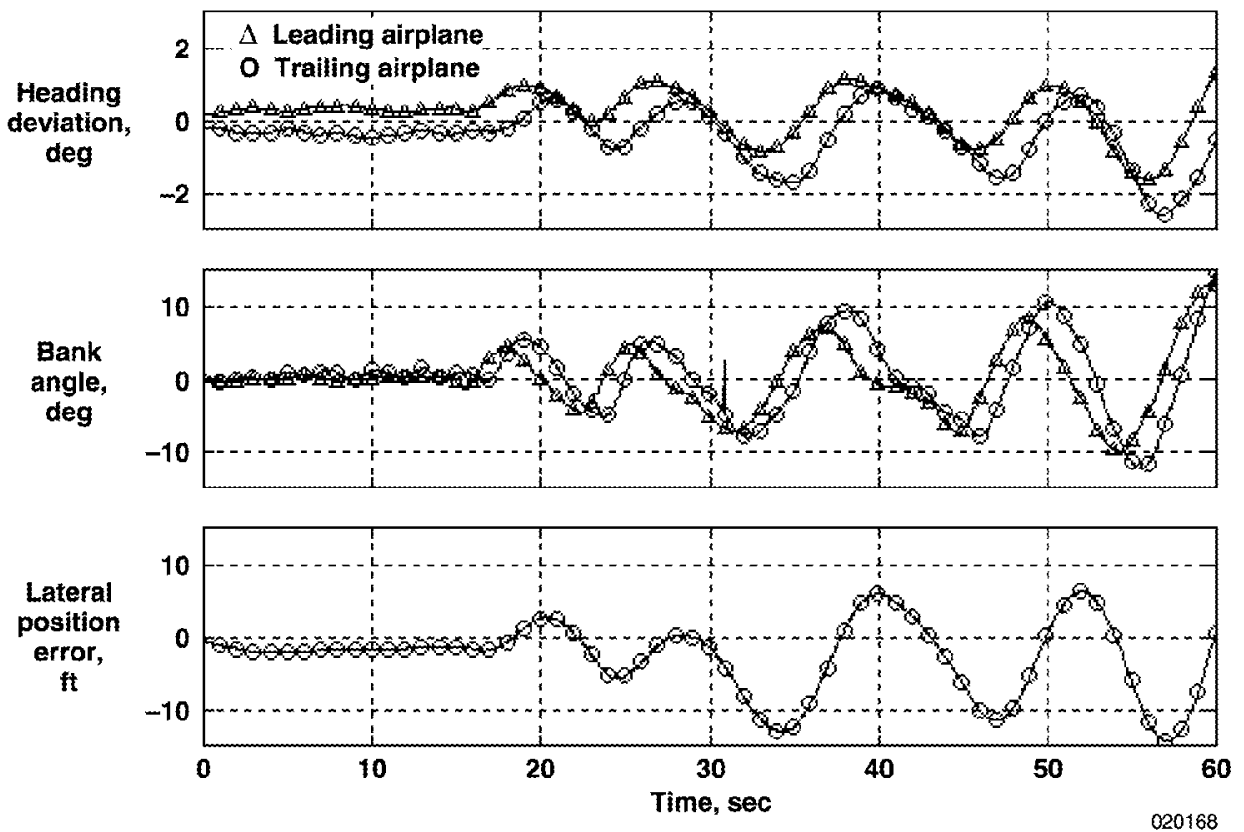

Figure 12. Gain set "C" lateral dynamic response from flight 715. 


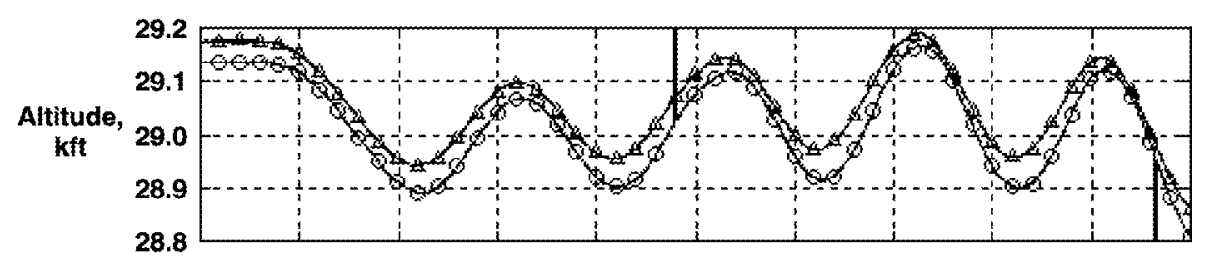

$\Delta$ Leading airplane o Trailing airplane
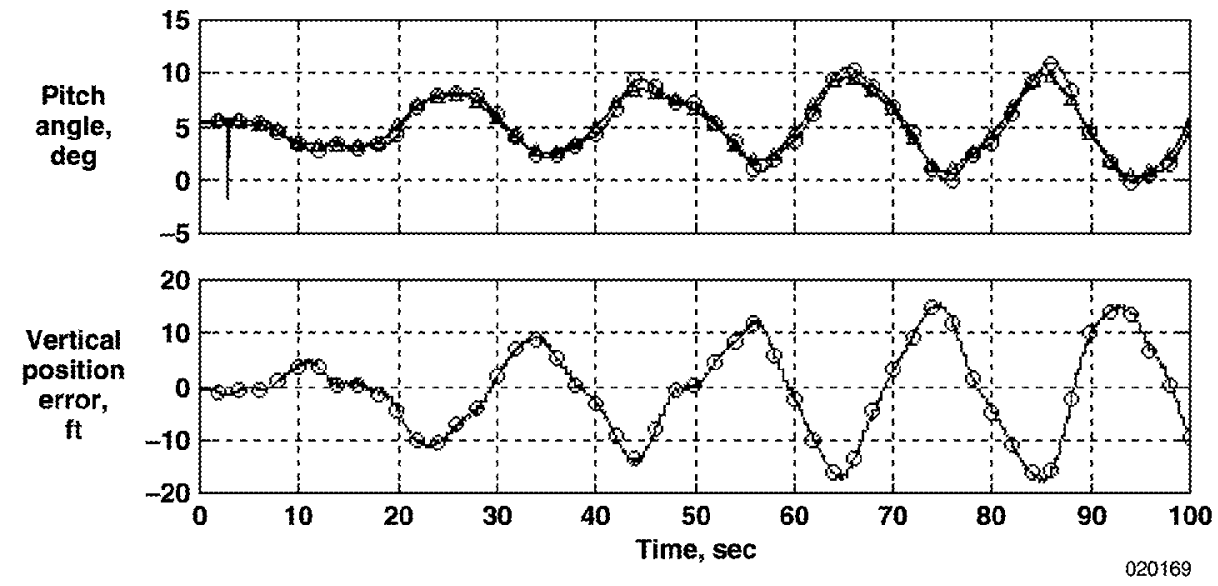

Figure 13. Gain set "C" vertical dynamic response from flight 717.

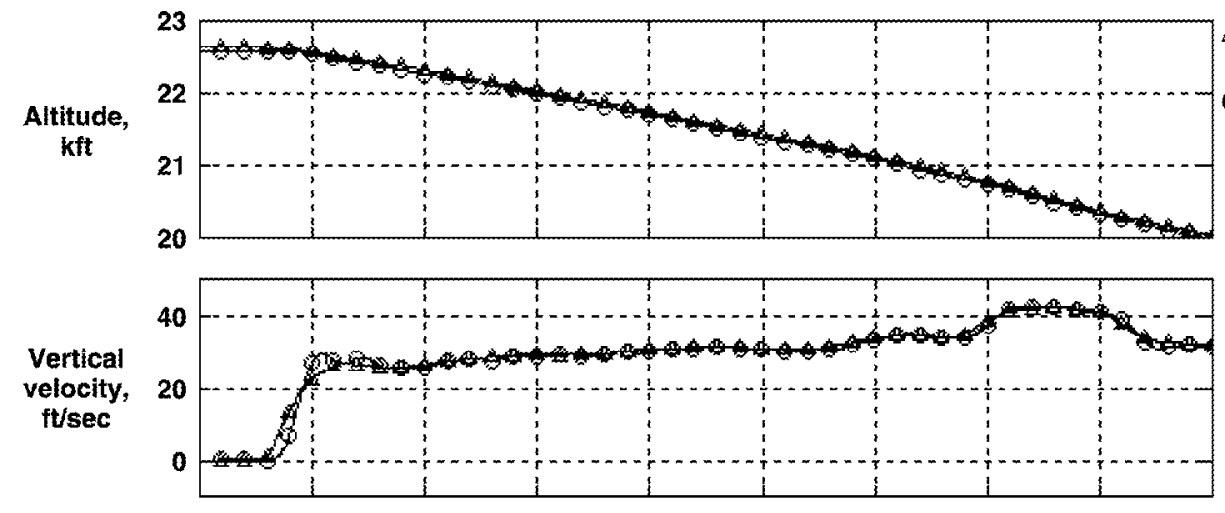
airplane o Trailing airplane

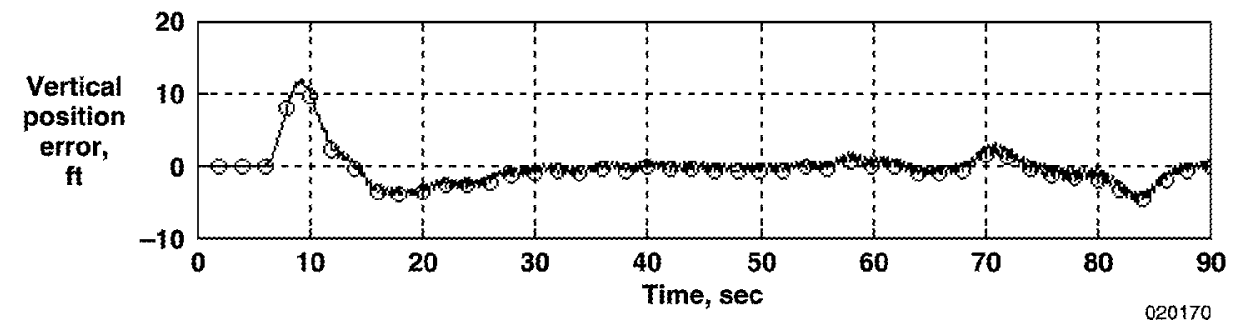

Figure 14. Gain set "D" vertical dive response from flight 717. 
The simulation vortex model had not been confirmed to accurately model the characteristics of real F/A-18 wingtip vortices, so the response of the Phase 0 formation autopilot system to vortex effects was also tested in flight. The results, shown in figure 15, were similar to the simulation study. With the wingtips of the two aircraft spaced approximately $10-\mathrm{ft}$ apart and the leading airplane $15 \mathrm{ft}$ above, the trailing airplane was commanded closer to the vortex core in 5 -ft vertical increments. Upon reaching the same altitude as the leading airplane, the trailing airplane appeared to stabilize, with approximately 0.1 in. of roll trim, at $150 \mathrm{sec}$. At this point, the trailing airplane was commanded 5-ft laterally closer to the vortex core. The control requirements associated with the vortex rolling moment then exceeded the bandwidth of the formation autopilot and caused the trailing airplane to exit the vortex. Because of large fluctuations in pilot-commanded throttle position to maintain nose-to-tail separation, no appreciable fuel flow reduction was measured.

The response similarities between simulation and flight improved confidence in the vortex model. Further simulation studies have shown that the removal of stick-path nonlinearities and the addition of roll rate feedback in the lateral axis significantly improve the vortex disturbance rejection capability of the formation autopilot. ${ }^{14,15}$

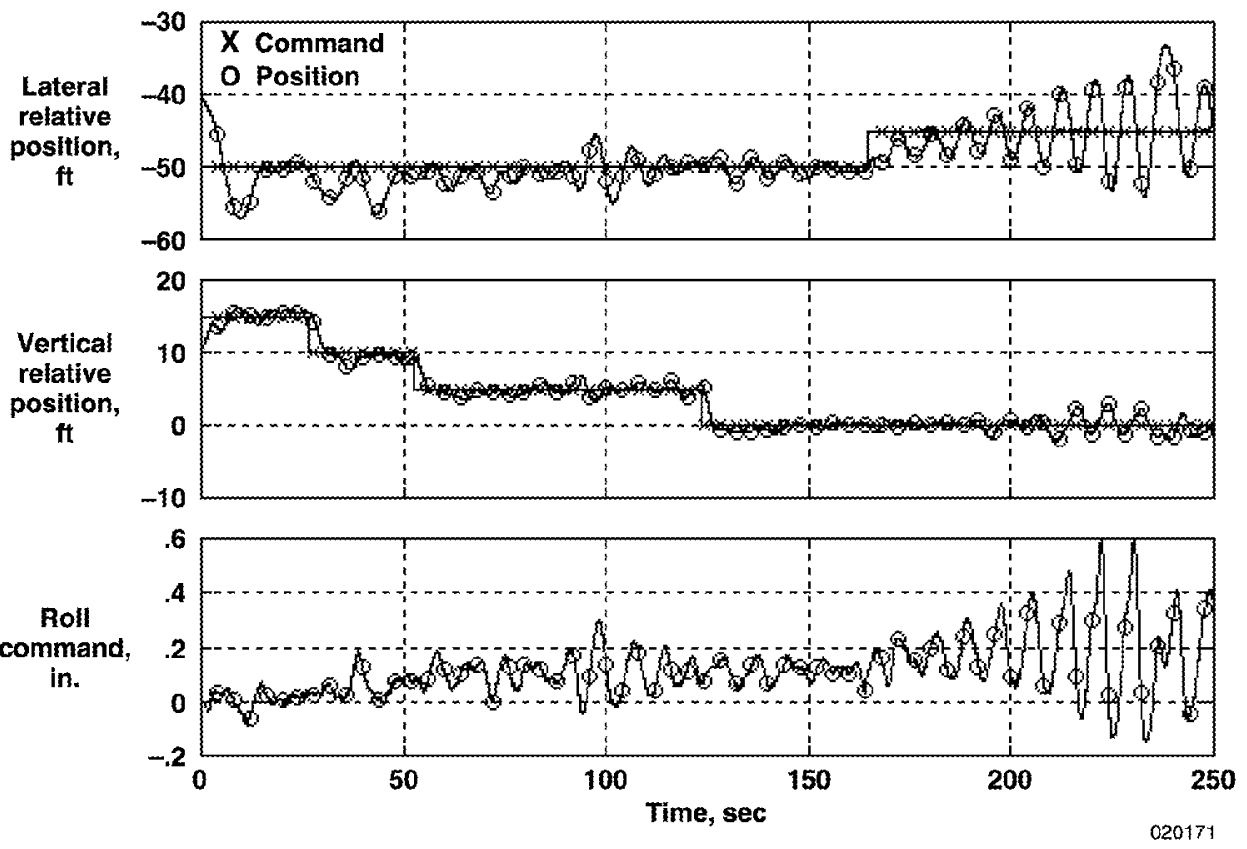

Figure 15. Gain set "D" vortex immersion flight test results from flight 718. 


\section{Concluding Remarks}

The Autonomous Formation Flight project successfully designed, implemented, and flight-tested an F/A-18 formation autopilot system that combines inertial and global positioning system measurements to maintain precision station-keeping with another aircraft in formation. Four formation autopilot gain sets were tested, and each exceeded project design requirements for steady-state tracking accuracy. Steady-state tracking performance exceeded the goal of $\pm 10 \mathrm{ft}$ and typically showed values less than $\pm 5 \mathrm{ft}$. The complementary filter improved tracking results by eliminating inertial system initialization and drift errors. Step responses were well-damped, and simultaneous maneuvering showed no cross-coupling issues. Pilot comments indicate that the system demonstrated an acceptable level of performance for a formation flight autopilot.

The formation autopilot also showed acceptable behavior beyond the scope of its design concept during maneuvering flight. More phase lag was observed in the lateral axis than in the vertical, although both axes remained stable. Tracking response during descending flight was excellent, exceeding the steady-state design requirement of $\pm 10 \mathrm{ft}$.

The strong level of agreement between simulation predictions and aircraft response in flight has provided confidence in the design tools used in development. The performance of the formation autopilot demonstrated the feasibility of this type of tracking system for more advanced applications.

\section{$\underline{\text { References }}$}

${ }^{1}$ Beukenberg, Markus and Dietrich Hummel, "Aerodynamics, Performance and Control of Airplanes in Formation Flight," ICAS Proceedings 1990: 17th Congress of the International Council of the Aeronautical Sciences, Sept. 1990, pp. 1777-1794.

${ }^{2}$ Hummel, Dietrich, "Formation Flight as an Energy-Saving Mechanism," Israel Journal of Zoology, vol. 41, 1995, pp. 261-278.

${ }^{3}$ Military Specification, Flight Control Systems-General Specifications for Design, Installation and Test of Piloted Aircraft, MIL-F-9490D, 1975.

${ }^{4}$ Gera, Joseph and John T. Bosworth, Dynamic Stability and Handling Qualities Tests on a Highly Augmented, Statically Unstable Airplane, NASA TM-88297, 1987.
${ }^{5}$ Sitz, Joel R., F-18 Systems Research Aircraft Facility, NASA TM-4433, 1992.

${ }^{6}$ Carter, John F. and P. C. Stoliker, Flying Quality Analysis of a JAS 39 Gripen Ministick Controller in an F/A-18 Aircraft, NASA TM-2000-209024, 2000.

${ }^{7}$ Carter, John F., Production Support Flight Control Computers: Research Capability for F/A-18 Aircraft at Dryden Flight Research Center, NASA TM-97-206233, 1997.

${ }^{8}$ Carter, John and Mark Stephenson, Initial Flight Test of the Production Support Flight Control Computers at NASA Dryden Flight Research Center, NASA TM-1999-206581, 1999.

${ }^{9}$ Ryan, Jack, et a1., Data Synchronization Discrepancies in a Formation Flight Control System, NASA TM-2001-210720, 2001.

${ }^{10}$ Parkinson, Bradford W., "GPS Error Analysis," Global Positioning System: Theory and Applications, vol. 1, American Institute of Aeronautics and Astronautics, Inc., Washington, D. C., 1996, pp. 469-483.

${ }^{11}$ Brown, Robert Grover and Patrick Y. C. Hwang, Introduction to Random Signals and Applied Kalman Filtering, John Wiley \& Sons, New York, 1997.

${ }^{12}$ Tischler, Mark B., et al., "CONDUIT-A New Multidisciplinary Integration Environment for Flight Control Development," AIAA-97-3773, 1997.

${ }^{13}$ Vachon, M. Jake, Ronald J. Ray, Kevin R. Walsh, Kimberly A. Ennix, "Measured Performance Benefits During the Autonomous Formation Flight Program," AIAA-2002-4491, Aug. 2002.

${ }^{14}$ Lavretsky, Eugene, "F/A-18 Autonomous Formation Flight Control System Design," AIAA-2002-4757, Aug. 2002.

${ }^{15}$ Misovec, Kathleen, "Applied Adaptive Techniques for F/A-18 Formation Flight," AIAA-2002-4550, Aug. 2002. 
Public reporting burden for this collection of information is estimated to average 1 hour per response, including the time for reviewing instructions, searching existing data sources, gathering and maintaining the data needed, and completing and reviewing the collection of information. Send comments regarding this burden estimate or any other aspect of this collection of information, including suggestions for reducing this burden, to Washington Headquarters Services, Directorate for Information Operations and Reports, 1215 Jefferson Davis Highway, Suite 1204 , Arlington, VA 22202-4302, and to the Office of Management and Budget, Paperwork Reduction Project (0704-0188), Washington, DC 20503.

\begin{tabular}{|l|l|l|}
\hline 1. AGENCY USE ONLY (Leave blank) & $\begin{array}{l}\text { 2. REPORT DATE } \\
\text { August } 2002\end{array}$ & $\begin{array}{l}\text { 3. REPORT TYPE AND DATES COVERED } \\
\text { Technical Memorandum }\end{array}$ \\
\hline
\end{tabular}

4. TITLE AND SUBTITLE

5. FUNDING NUMBERS

An Overview of Flight Test Results for a Formation Flight Autopilot

6. AUTHOR(S)

WU $7063500 \mathrm{E} 82800 \mathrm{AFF}$

Curtis E. Hanson, Jack Ryan, Michael J. Allen, and Steven R. Jacobson

7. PERFORMING ORGANIZATION NAME(S) AND ADDRESS(ES)

8. PERFORMING ORGANIZATION

REPORT NUMBER

NASA Dryden Flight Research Center

P.O. Box 273

Edwards, California 93523-0273

H-2499

9. SPONSORING/MONITORING AGENCY NAME(S) AND ADDRESS(ES)

10. SPONSORING/MONITORING

AGENCY REPORT NUMBER

National Aeronautics and Space Administration

Washington, DC 20546-0001

NASA/TM-2002-210729

11. SUPPLEMENTARY NOTES

Also presented at the AIAA Guidance, Navigation and Control, AIAA Atmospheric Flight Mechanics, AIAA Modeling and Simulation Technologies, and AIAA/AAS Astrodynamics Conferences, Monterey, California, AIAA-2002-4755.

\begin{tabular}{l|l} 
12a. DISTRIBUTION/AVAILABILITY STATEMENT & 12b. DISTRIBUTION CODE
\end{tabular}

Unclassified-Unlimited

Subject Category -08

This report is available at http://www.dfrc.nasa.gov/DTRS/

13. ABSTRACT (Maximum 200 words)

The first flight test phase of the NASA Dryden Flight Research Center Autonomous Formation Flight project has successfully demonstrated precision autonomous station-keeping of an F/A-18 research airplane with a second F/A-18 airplane. Blended inertial navigation system (INS) and global positioning system (GPS) measurements have been communicated across an air-to-air telemetry link and used to compute relative-position estimates. A precision research formation autopilot onboard the trailing airplane controls lateral and vertical spacing while the leading airplane operates under production autopilot control. Four research autopilot gain sets have been designed and flight-tested, and each exceeds the project design requirement of steady-state tracking accuracy within 1 standard deviation of $10 \mathrm{ft}$. Performance also has been demonstrated using single- and multiple-axis inputs such as step commands and frequency sweeps. This report briefly describes the experimental formation flight systems employed and discusses the navigation, guidance, and control algorithms that have been flight-tested. An overview of the flight test results of the formation autopilot during steady-state tracking and maneuvering flight is presented.

\begin{tabular}{|c|c|c|c|}
\hline \multirow{2}{*}{\multicolumn{3}{|c|}{$\begin{array}{l}\text { 14. SUBJECT TERMS } \\
\text { Formation autopilot, Formation flight, Station keeping }\end{array}$}} & \multirow{2}{*}{$\begin{array}{l}\text { 15. NUMBER OF PAGES } \\
17 \\
\text { 16. PRICE CODE } \\
\text { A03 }\end{array}$} \\
\hline & & & \\
\hline $\begin{array}{l}\text { 17. SECURITY CLASSIFICATION } \\
\text { OF REPORT }\end{array}$ & $\begin{array}{l}\text { 18. SECURITY CLASSIFICATION } \\
\text { OF THIS PAGE }\end{array}$ & $\begin{array}{l}\text { 19. SECURITY CLASSIFICATION } \\
\text { OF ABSTRACT }\end{array}$ & 20. LIMITATION OF ABSTRACT \\
\hline Unclassified & Unclassified & Unclassified & Unlimited \\
\hline
\end{tabular}

